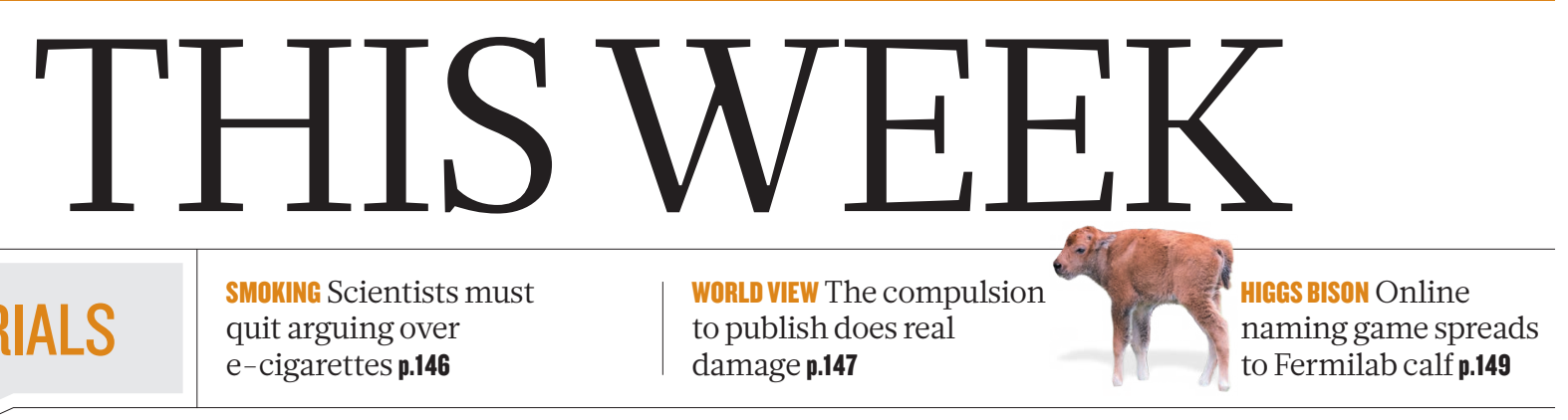

EDITORIALS quit arguing over e-cigarettes $\mathbf{p} .146$

Mothers' milk

\author{
The safe use of medicines during breastfeeding is not an easy topic to study, but new parents \\ deserve better information on the risks and benefits.
}

$\mathrm{W}$ hen Janet Woodcock first started to practise medicine nearly 40 years ago, she quickly realized that her training had not equipped her to deal with a common dilemma. New mothers were being encouraged to breastfeed their children, but was it safe to do so if they were taking medication? "I had never received one word of information on that situation," says Woodcock, who now heads the US Center for Drug Evaluation and Research at the Food and Drug Administration (FDA).

Woodcock's patients, she says, were "frantic" to do the best for their babies. But in the absence of data on whether and how a medicine could affect their newborn, mothers were often forced to decide between their own health and their child's. The prevailing medical advice - then and now - was, in case of doubt, to stop breastfeeding.

The situation has improved, she said at a workshop on medications and breastfeeding convened by the FDA late last month - but not nearly enough. Almost $90 \%$ of breastfeeding mothers in the United States take a medicine of some sort. For many of those drugs - including commonly used medicines to treat high cholesterol and diabetes - doctors still don't know how to counsel their patients. At the workshop, researchers illustrated how little research is done to answer those questions: a search of grants issued by the US National Institutes of Health (NIH) on the topic shows only a handful of studies, and most focus on HIV medicines.

The dearth of research comes amid renewed massive public-health pushes across the world to encourage mothers to breastfeed. Breastfeeding has been linked to fewer infections and less time in the paediatrician's office, saving parents anxiety and health systems cash. The need is particularly acute in countries where money and clean water to buy and prepare baby formula are limited. More than a decade into the twentyfirst century, whether the medicines a breastfeeding mother takes are safe is a question that demands more attention.

It is undeniably difficult to conduct most clinical studies of infants. There are logistical challenges: an exhausted mother may not be keen to attend extra medical visits, and may not want to divulge the medicines she has chosen to take while breastfeeding. There are ethical challenges: clinical trials involving babies are fraught with questions about informed consent, for example. And there are financial challenges, too.

These problems have received little public attention, yet the barriers can be surmounted. At the FDA workshop, several researchers presented their success stories and lessons learned. Seemingly small measures, even changing a nappy or rocking a baby while a mother visits a clinic, can encourage women to make the effort to participate in a study. Ethical questions can be addressed though careful study design, and by paying attention to the benefits of the extra monitoring for both individual babies and for mothers. And in 2014, the FDA took a step towards raising the visibility of the matter by improving drug labels to better display what is known - and unknown - about the safety of a given drug for breastfeeding mothers and their children.

Some researchers are already gathering data and building resources. Researchers at the University of California, San Diego, for instance, have launched the Mommy's Milk Human Milk Research Biorepository - the first of its kind, they say.

At first glance, it might not seem like sexy science for a basic researcher: the details of how particular drugs are metabolized are more
"Ethical questions can be addressed through careful study design." vant information and possibly even advance fields in a fundamental way. Funders such as the NIH have taken laudable steps to address women's health issues at the level of basic research, by ensuring that animal studies include females when possible and relevant. More researchers and funders should build on that momentum and address the impact of medicines on breastfeeding mothers and their children.

\section{Market forces}

\section{A European plan to commercialize quantum technologies needs a bold goal.}

$\mathrm{N}$ obody ever went broke by underestimating the intelligence of the American public, goes the famous line by the US editor Henry Louis Mencken. It's actually a paraphrase, but the meaning is clear: to make money, it is safe to assume that nobody knows anything.

By rights, then, quantum physics should be extremely profitable. The subject is often used as shorthand for knowledge that is reserved for a small intellectual elite, with everyone else left scratching their heads. As Canadian Prime Minister Justin Trudeau showed last month, the quantum world is so weird that to mount even a halfdecent explanation of its basic principles can bring praise and plaudits.

Can this widespread ignorance - the puzzlement at how cats can be both alive and dead, or how particles can exist in two places at once - be capitalized on? The European Commission believes that it can. Next week, it will release a plan for a continent-wide drive to turn the mysteries of quantum physics into hard cash.

This plan, called the European Quantum Manifesto, will be officially released in the Dutch town of Delft, where the commission hopes a 
revolution will be born. Eyeing China, Australia, Canada and other countries that have invested huge sums of money in quantum technology, Europe does not want to miss out. With $€ 1$ billion (US $\$ 1.1$ billion) of funding, scientists and businesses will be expected to translate quantum research into quantum products to create "a more sustainable, more productive, more entrepreneurial and more secure European Union".

These are great expectations. Europe is no doubt encouraged by the various quantum technologies that have matured in recent years. Quantum sensors, for example, can achieve high sensitivity and resolution through quantum superposition or entanglement, outperforming classical sensors in various imaging applications. Strategic use of funds could indeed take quantum sensors to market in a few years.

But for most quantum technologies, the path to commercialization is much longer and more contrived. The arguable peak of quantum technologies - the construction of a universal quantum computer - is decades, and billions of euros of targeted investment, away. But it promises perhaps the greatest gains: substantially greater power for key computations, such as simulations of chemical reactions and - maybe - machine learning.

Revolutions happen through popular uprising and not through carefully directed government investment. At some point, investors, entrepreneurs and academics are supposed to conspire on this revolution without directives from above. Hence the European Quantum Manifesto seeks to mobilize a broad base of quantum technologists. Specifically, it plans an environment in which small, high-potential quantum-tech businesses can thrive.

Given that a large majority of start-up firms fail, how is this plan supposed to work in the risky and unproven quantum-technology business? Predicting the likely outcome of the European Commission's plan is as hard as determining whether Schrödinger's cat is dead or alive without opening its box.

Can we peek inside the box to get some insights on how this commercial future might unfold? Nature has designed an experiment to try.

The project (see go.nature.com/53iiw6) trained seven young quantum physicists to conceive and evaluate business ideas in quantum technologies. The project culminated in a presentation day last week at Nature's London office, where the physicists' ideas were scrutinized by a panel of experienced entrepreneurs and leaders in quantum technologies.

A PhD student from University College London invented a quantuminspired accelerometer with a relatively safe and clear route to market.

"This is one project that should not have to be in several places at once."
And two postdocs from the University of New South Wales in Sydney, Australia, have the ambition to outshine Google and IBM and build a universal quantum computer based on silicon qubits.

Two of the five ideas that were presented an invention that permits quantum computers to be linked, and a start-up that will design quantum machine-learning algorithms - set out to depend on the few companies and groups who have already invested huge sums of money to try to build quantum-computing hardware. Both ideas are betting on being able to sell their products to only a few customers. It sounds like a risky strategy, but it might indicate a way to create and sustain the necessary critical mass of start-ups that the European Quantum Manifesto is aiming for. Focusing investment on one high-risk, high-gain goal — such as a universal quantum computer — could create a string of start-ups that each specialize in one integral component or aspect.

Still, it is unlikely that Europe's quantum-technology initiative will take this route. Given the many scientific goals in the manifesto, the authors seem to hope that the plan will have its own quantum properties and be able to address all the goals simultaneously. That looks like a mistake. It would be a missed opportunity if the quantum world that the commission hopes to create is hamstrung by the small steps and endless compromise that haunt other European projects. The initiative needs a clear and a bold goal. This is one project that should not have to be in several places at once.

\section{Smoke out}

\section{Scientists should unite over electronic-cigarette regulation, or big tobacco will step in.}

S ix million people die every year as a result of tobacco smoking, according to an estimate by the World Health Organization. It is a number worth keeping in mind as the scientific disputes over electronic cigarettes continue to smoulder.

The US Food and Drug Administration last week announced a "historic rule" that gives it the right to regulate e-cigarettes — which vaporize nicotine - as it does tobacco products. Nearly all e-cigarettes will now have to go through an approval process, with sales to young people prohibited, and health warnings included on packaging and advertisements.

Sylvia Burwell, the US Secretary of Health and Human Services, noted that e-cigarette use is shooting up among young people in the United States, "creating a new generation of Americans who are at risk of addiction", even as cigarette smoking continues to decline.

Some states are already ahead of federal law - earlier this month, California defined e-cigarettes as tobacco products, with all that that entails. The European Union is also set to take a tougher stance. An EU-wide directive that comes into force this year on tobacco products will control nicotine content.

These 'vaping' devices have split researchers. Some see a route to end the tobacco scourge. Conventional medicine provides few escapes from nicotine addiction, and the speed at which smokers embrace electronic systems seems to be a blessing. If the world's smokers switched from burning to vaping, that figure of six million deaths would fall.

But other scientists see problems. They fear that electronic devices subvert the message that smoking is bad, and offer people a nicotine fix in places where cigarettes have long been excluded. They fear a new age of nicotine, and that the six-million figure will rise.

This difference of opinion has spilled messily over into the research arena. Published studies are ruthlessly spun or picked apart by opposing sides. Sometimes the fight happens even before publication, with journalists sent quotes under embargo that critique claims and conclusions before they are publicly available.

Both sides are acting in good faith, but their arguments and increasingly entrenched positions frequently generate more heat than light. To progress, researchers on both sides must establish what evidence should be gathered to answer the central question: how can e-cigarette use and regulation lead to the largest possible reduction in deaths from tobacco? As part of this process, they should identify key data that, if forthcoming, would change their current view.

There is good reason for researchers to come together on this, and quickly. Conventional tobacco firms are grabbing an increasingly large share of the e-cigarette market. This should concern everyone - and focus minds. Few industries have historically been quite so willing to dissemble, and to market products with so few benefits and so many harms.

Researchers should remain focused on the enemy that needs to be fought - the horrific harm caused by tobacco. Disputes are part of science. They must be conducted in the open, and no researcher - and $\rightarrow$ NATURE.COM To comment online, click on Editorials at: go.nature.com/xhunqv no piece of research - can be immune from criticism. But the tobacco-science community must find a way forward. It is not hyperbole to say that millions of lives are at stake. Six million of them are, every year. 